\title{
High risk pregnancy and Fetal outcome at Shree Birendra Hospital
}

\author{
Arju Chand Singh, Ratna Khatri, Sadikchya Singh Rana, Rosy Malla, Sumana Thapa, Indira Acharya \\ Department of Obstetrics and Gynaecology, Shree Birendra Hospital, Kathmandu, Nepal.
}

Correspondence: Dr Arju Chand Singh, Department of Obstetrics and Gynecology, Shree Birendra Hospital, Kathmandu, Nepal.

Email: arju.ravi@gmail.com

\begin{tabular}{l} 
Abstract \\
\hline \hline Introduction: High risk pregnancy is a major cause of morbidity and mortality in a developing \\
country. These patients are recognized in the initial prenatal office visit as they have a poor obstetrical \\
history or a well recognized medical complication however; pregnancy becomes high risk because \\
they develop unexpected complications in the course of otherwise normal pregnancies. The objective \\
of this study is to identify various type of high risk pregnancy and fetal outcome. \\
Methods: This was a descriptive study conducted in Shree Birendra military hospital over a period \\
of 9 months. Patients were recognized as high risk during antenatal visit and during admission. They \\
were followed till delivery. The case records of all high risk pregnancy with their fetal outcome were \\
analyzed. Statistical analysis was done using simple percentage. \\
Results: Total deliveries during study period was 626. High risk pregnancy identified were 99 \\
(15.81\%). Previous lower segment cesarean section was the most common identified high risk \\
pregnancy 34 (5.43\%) followed by young primigravida $3.19 \%$, breech $2.23 \%$. There were total 13 \\
low birth weight baby (13.13\%) and 2 stillbirth ( $2 \%)$ as fetal outcome. \\
Conclusion: Identification of high risk pregnancy during antenatal period will reduce adverse \\
perinatal outcome. \\
Key words: Cesarean section; Fetal outcome; High risk pregnancy.
\end{tabular}

\section{Introduction}

High risk pregnancy is that with a significant probability for poor maternal or fetal outcome. A pregnancy is "high risk" or "complicated" when the life or health of the mother or baby may be at risk.

Pregnancy can be considered a high risk pregnancy for a variety of reasons. Factors are divided into maternal and fetal viz, maternal factors include age $(<19$ years and $>35$ years), weight (pre-pregnancy weight $<100 \mathrm{lb}$ or obesity), height (4.7 feet), history of complication during previous pregnancy (preterm delivery, stillbirth, large baby, preeclampsia), Rh incompability, gestational diabetes, AIDS. Fetal factors exposure to infection (Hepatitis, Syphilis, Rubella), drugs (phenytoin, Warfarin, Lithium). ${ }^{1}$
In some cases these patients are recognized in the initial prenatal office visit because they have a poor obstetrical history or a well recognized medical complication. In other cases women become high risk pregnancy because they develop unexpected complications in the course of otherwise normal pregnancies. They can be identified only if the women has access to prenatal care. Limiting factor preventing the identification of those at risk is poverty and the quality of prenatal care itself.

To facilitate the identification of those, most prenatal records incorporate a list of high risk factors that should be systematically checked during the first prenatal visit to find women at risk. So this study was conducted to identify 
various type of high risk pregnancy and fetal outcome as these patients require sophisticated maternal and fetal surveillance and in many occasion different management decisions in order to optimize their outcome. The objective of this study is to identify various type of high risk pregnancy and fetal outcome.

\section{Methods}

This was a descriptive study conducted in Shree Birendra military hospital in the department of obstetrics and gynecology over a period of nine months in all cases of high risk pregnancy admitted during the study period and fetal outcome was seen. Patients were recognized as high risk during antenatal visit as well as during admission. They were followed till delivery. Case records of hospital with all high risk pregnancy and their fetal outcome were analysed. Parameters analysed as high risk pregnancy were young primigravida, elderly primigravida, Short stature, obesity, hypertensive disorders of pregnancy, multiple pregnancy, malpresentation, subfertility, Previous cesarean section, Placenta Previa, Gestational Diabetes mellitus, Bad obstetrics history, medical diseases, Rhesus negative, obstetric cholestasis of pregnancy.Fetal parameters that were analysed were stillbirth and low birth weigh.Statistical analysis was done using simple percentage.

\section{Results}

Total number of deliveries during study period was 626 . Total high risk pregnancy identified were 99 (15.81\%). Out of which the most common was previous cesarean section $5.43 \%$ who had undergone repeat cesarean section except two had vaginal birth after cesarean section as they came in active phase of labor. There was $3(8.82 \%)$ low birth weight baby.

Young primigravida 3.19\% who all had normal deliveries expect two had emergency cesarean section for fetal distress and cephalopelvic disproportion. There were 5 teenage mothers of age 16 to 17 years and 15 of age group 18 to 19 years. Low birth weight baby was $3(15 \%)$.

Breech was $2.23 \%$ out of which 11 were primi breech, 2 multipara and all had cesarean section except one had vaginal breech delivery. There was 2 (14\%) low birth weight baby.

Rhesus negative was $1.43 \%$. Hypertensive disorder of pregnancy was $0.95 \%$.

There were $0.63 \%$ short stature all underwent cesarean section. There were $0.47 \%$ high-risk pregnancy of hypothyroidism, subfertility and obstetric cholestasis of pregnancy. One had preterm vaginal delivery at 32 week gestation, another had sudden intrauterine fetal death with fresh still birth at 33 week gestation.
There were $0.15 \%$ identified high-risk pregnancy with VDRL, APH and thalassemia with 100\% low birth weight baby.

Table 1. Various type of high risk pregnancy $(n=99)$.

\begin{tabular}{lll} 
& \multicolumn{1}{c}{ Characteristics } & No \\
1 & Previous cesarean section & 34 \\
2 & Young primigravida & 20 \\
3 & Breech & 14 \\
4 & Rhesus negative & 9 \\
5 & Hypertensive disorder of pregnancy & 6 \\
6 & Short stature & 4 \\
7 & Subfertility & 3 \\
8 & Hypothyroidism & 3 \\
9 & Obstetric cholestasis in pregnancy & 3 \\
10 & Thalessemia & 1 \\
11 & Antepartum hemorrhage & 1 \\
12 & VDRL & 1
\end{tabular}

Two underwent emergency cesarean section for abruption placenta at 29 week gestation and impending pre eclampsia at 36 week gestation. One had termination of pregnancy at 25 week gestation with fresh still birth. There were $2(33 \%)$ low birth weight and $1(16.6 \%)$ stillbirth.

Table 2. Fetal outcome in relation to high risk pregnancy.

\begin{tabular}{|c|c|c|c|}
\hline \multirow{2}{*}{\multicolumn{2}{|c|}{ High risk pregnancy }} & \multirow{2}{*}{\multicolumn{2}{|c|}{ Characteristics }} \\
\hline & & & \\
\hline 1 & $\begin{array}{l}\text { Previous cesarean } \\
\text { section }\end{array}$ & & 3 \\
\hline 2 & Young primigravida & & 3 \\
\hline 3 & Breech & & 2 \\
\hline 4 & Rhesus negative & & \\
\hline 5 & $\begin{array}{l}\text { Hypertensive } \\
\text { disorder of prenancy }\end{array}$ & 1 & 2 \\
\hline 6 & Short stature & & \\
\hline 7 & Subfertility & & \\
\hline 8 & Hypothyroidism & & \\
\hline 9 & $\begin{array}{l}\text { Obstetric cholestasis } \\
\text { in pregnancy }\end{array}$ & 1 & 2 \\
\hline 10 & Thalessemia & & 1 \\
\hline 11 & $\begin{array}{l}\text { Antepartum } \\
\text { hemorrhage }\end{array}$ & & \\
\hline 12 & VDRL & & \\
\hline
\end{tabular}


Two (66.6\%) low birth weight baby and one (33.3\%) stillbirth with obstetric cholestasis of pregnancy.

\section{Discussion}

Pregnancy is a time of unparallel joy and expectation. Families can cope more successfully with a high risk pregnancy with appropriate medical intervention, education and strong support system with proper care.

These days parturients are now heavier than they used to be, older age, number of premature and low birth weight neonates has increased, multiple gestation has increased from the use of ART. Low birth weight $3(8.82 \%)$ has been observed as the only neonatal complication. ${ }^{2}$ All these changes have been associated with an increased risk of cesarean section. Trial of labor was not attempted as risk of delivery related perinatal death was more than 11 times that of women having a planned repeat cesarean section. ${ }^{3}$ Trial of labor may lower the incidence of minor complication (wound infection) but not the number of major complications (uterine rupture, hysterectomy, septicemia). ${ }^{4}$ The proportion of women who attempt vaginal delivery after prior cesarean delivery has decreased largely because of concern about safety. ${ }^{5}$

Second most common high risk pregnancy identified were young primigravida and these all teenage mothers had no complication like preeclampsia, premature onset of labor, anemia, IUGR except one had pregnancy induced hypertension as shown in other studies. Increased incidence of LBW in teenage pregnancy has also been reported which are similar to that observed in our study. $6,7,8$

In this study other common identified high risk pregnancy were Rhesus negative and Breech. The risk of Rhesus alloimmunization is 6/1000 birth which is not comparable with this study as it has no cases of Rhesus alloimmunization. ${ }^{1}$ The main cause of Rhesus sensitization in present practice are lack of awareness. In earlier times fetal prognosis following fetal hydrops was poor but with facilities for intrapartum fetal transfusion prognosis is vastly improved. In this study all were term breech. Fetal and neonatal mortality and morbidity are higher for fetus in breech presentation and was significantly lower for elective cesarean section as compared to vaginal delivery. These are due to associated factors like preterm delivery, congenital malformation, PROM, placenta previa. ${ }^{9}$ Fetus with low birth weight showed high mortality rate and perinatal death was more common among with LBW than those weighing $2.5 \mathrm{~kg} .{ }^{10}$ Cervical head entrapment and fetal bradycardia were ominous intrapartum complication. ${ }^{11}$ But this study showed low birth weight as the only neonatal morbidity without any intrapartum complication. In this study no maternal complication like anemia, pregnancy induced hypertension, postpartum hemorrhage, intrauterine growth retardation seen with pregnancy with hypothyroidism $(0.47 \%)$ as reported by K. Buckshee because thyroid hormone concentration was maintained at optimum level in all these patients. ${ }^{12}$

Low birth weight and still birth was the fetal outcome in hypertensive disorders of pregnancy in this study as reported by other studies other than eclampsia, HELLP syndrome, cerebral hemorrhage, acute renal failure and pulmonary complication. . $^{13,14,15}$

Obstetrics cholestasis in pregnancy has been associated with a high incidence of stillbirth and preterm deliveries as this study showed. Intensive fetal surveillance including amniocentesis for meconium and induction of labor at term may reduce SB rate in high risk condition..$^{16,17}$ There were no low birth weight baby, preterm deliveries, stillbirth, neonatal mortality in case of short stature mothers in our study as showed by other studies. ${ }^{18}$

\section{Conclusion}

Most common identified high risk pregnancy was previous cesarean section. Number of high risk pregnancy can be identified before pregnancy occurs, the women will benefit considerably from meeting with the obstetrician to analyze her high risk factors and life style modification that she may adopt to maximize the outcome of pregnancy.

\section{References}

1. Arias F, Daftary S,Bhide A.Practical guide to high risk pregnancy and delivery:A South Asian perspective .3rd edn.India, 2011.

2. Jeffrey L,Ecker,Fredric D,Frigolette Jr.Cesarean delivery and the risk- Benefit calculus.The New England Journal of medicine.2007;356:885-88. https://doi.org/10.1056/ NEJMp068290, PMid:17329693

3. Smith GC et al.Risk of perinatal death associated with labour after previous cesarean section in uncomplicated term pregnancies.JAMA.2002;287(20):2684-90. https:// doi.org/10.1001/jama.287.20.2684, PMid:12020304

4. Rageth, J.Christoph MD,Juze, Claudia MD. Delivery after previous cesarean section . A risk Evaluation.Obs and Gynecology.1999;93(3):332-37. PMid:10074973

5. Mark B Landon, John C. Haut, Kenneth J. Leveno, Maternal and perinatal outcomes associated with a trial of labour after prior cesarean section 
delivery. New England J Med.2004;351:2581-89. https://doi.org/10.1056/NEJMoa 040405 PMid: 15598960

6. Ashok Kumar,ej ingh,Supaina Basu,Sulekha Pandey, V. Bhargava. Outcome of teenage pregnancy .Indian Journal of Pediatrics .2007;74:927-31. https://doi.org/10.1007/s 12098-007-0171-2 PMid:17978452

7. Watcharaseranee $\mathrm{N}$ et al.The incidence and complication of teenage pregnancy at Chonbur hospital.J med Assoc Thai.2006;89(4):118-23.

8. Kayastha S, Pradhan A.Obstetric outcome of teenage pregnancy.NJOG.2012;7(2):29-32.

9. Gifford DS, SC Morton, M Foske,K Kahn. A metaanalysis of infant outcomes after breech delivery.Obstet Gynaecol.1995;85:1047-54. https://doi.org/10.1016/0029-7844(95)00053-T

10. Mekbib TA. Breech delivery and fetal outcome:a review of 291 cases. Ethiop Med J.1995;33(3):175-82. PMid:7588656

11. Woods JR. Effects of low birth weight breech delivery on neonatal mortality. Obstet Gynecol.1979;53(6):735-40. PMid:572025

12. K. Buckshee. Hypothyroidism complicating pregnancy. Aust N Z J Obstet Gynecol. 1992;32(3):240-2. https://doi.org/10.1111/j.1479-828X.1992.tb01956.x

13. Lin CC et al. Fetal outcome in hypertensive disorders of pregnancy. Am J Obstet Gynecol. 1982;142(3):255-60. https://doi.org/10.1016/0002-9378(82)90727-X

14. Singh A, Singh S, Fetal outcome in hypertensive disorders of pregnancy.Medical Journal of Shree Birendra Hospital.2013;12(1):8-10. https://doi.org/10.3126/mjsbh.v12i1.9083

15. Ferrazzani $\mathrm{S}$ et al. Neonatal outcome in hypertensive disorders of pregnancy.Early Hum Dev.2011;87(6):445-9. https://doi.org/10.1016/j.earlhumdev.2011.03.005 PMid:21497462

16. Fisk NM et al. Fetal outcome in obstetric cholestasis. $\mathrm{Br} \quad \mathrm{J}$ Obstet Gynecol.1988;95(11);1137-43. https://doi.org/10.1111/j.1471-0528.1988.tb06791.x PMid:3207643
17. Wikstrom Shemer e, Marschall HU, Widvigsson JF,Stephansson O. Intrahepatic cholestasis of pregnancy and associated adverse pregnancy and fetal outcomes- 12 year population based cohort study.BJOG.2013;120(6):717. https://doi.org/10.1111/1471-0528.12174 PMid:23418899

18. X Zhang, SL Mimford,S cnattingius,EF Schisterman,MS Kramer. Reduced birthweight in short or primiparous mothers. Physiological or path 